\title{
A Predictive Mimicker of Fracture Behavior in Fiber Reinforced Concrete Using Machine Learning
}

\author{
Sikandar Ali Khokhar, Touqeer Ahmed, Rao Arsalan Khushnood *, Syed Muhammad Ali and Shahnawaz
}

check for updates

Citation: Khokhar, S.A.; Ahmed, T.; Khushnood, R.A.; Ali, S.M.;

Shahnawaz A Predictive Mimicker of Fracture Behavior in Fiber Reinforced Concrete Using Machine Learning. Materials 2021, 14, 7669. https:// doi.org/10.3390/ma14247669

Academic Editor: Karim Benzarti

Received: 6 November 2021

Accepted: 25 November 2021

Published: 12 December 2021

Publisher's Note: MDPI stays neutral with regard to jurisdictional claims in published maps and institutional affiliations.

Copyright: (c) 2021 by the authors. Licensee MDPI, Basel, Switzerland. This article is an open access article distributed under the terms and conditions of the Creative Commons Attribution (CC BY) license (https:// creativecommons.org/licenses/by/ $4.0 /)$.
Nust Institute of Civil Engineering (NICE), School of Civil and Environmental Engineering (SCEE), National University of Sciences and Technology (NUST), Sector H-12, Islamabad 44000, Pakistan; skhokhar.bece18nice@student.nust.edu.pk (S.A.K.); tahmed.bece18nice@student.nust.edu.pk (T.A.); sali.bece18nice@student.nust.edu.pk (S.M.A.); shahnawaz.bece17nice@student.nust.edu.pk (S.)

* Correspondence: arsalan.khushnood@nice.nust.edu.pk

\begin{abstract}
Due to the exceptional qualities of fiber reinforced concrete, its application is expanding day by day. However, its mixed design is mainly based on extensive experimentations. This study aims to construct a machine learning model capable of predicting the fracture behavior of all conceivable fiber reinforced concrete subclasses, especially strain hardening engineered cementitious composites. This study evaluates 15x input parameters that include the ingredients of the mixed design and the fiber properties. As a result, it predicts, for the first time, the post-peak fracture behavior of fiber-reinforced concrete matrices. Five machine learning models are developed, and their outputs are compared. These include artificial neural networks, the support vector machine, the classification and regression tree, the Gaussian process of regression, and the extreme gradient boosting tree. Due to the small size of the available dataset, this article employs a unique technique called the generative adversarial network to build a virtual data set to augment the data and improve accuracy. The results indicate that the extreme gradient boosting tree model has the lowest error and, therefore, the best mimicker in predicting fiber reinforced concrete properties. This article is anticipated to provide a considerable improvement in the recipe design of effective fiber reinforced concrete formulations.
\end{abstract}

Keywords: FRC; machine learning; predictive model; efficient mimicker; post-peak response; fracture behavior; mechanical properties; ductility; strain hardening

\section{Introduction}

Due to brittle behavior, concrete absorbs significantly less energy as it shows an abrupt fracture in tension. Ductile materials can be coupled with concrete to improve tensile and energy absorption properties. Reinforced Cement Concrete (RCC) uses rebar to get better ductility and tensile strength. However, due to the larger diameter of the rebar, the cracks that rebar bridges are relatively larger, leading to durability issues [1]. The use of fibers has been increasing due to their enhanced mechanical and fracture properties. Fibers bridge the cracks at a micro-scale that controls crack width, improves crack resistance, and ensures better ductility.

Concrete reinforced with fibers can give either strain-softening or strain-hardening behavior. Mix that gives strain-hardening behavior is classified as Engineered Cementitious Composites (ECC). Earlier, it was thought that strain-hardening is achieved by only increasing the volume of fibers, but later it was found that fibers content is not the only controlling parameter. It is also the function of parameters such as:

- $\quad$ Fiber Properties: Mechanical properties, aspect ratio, and volume fraction;

- Matrix properties: Initial flaw size distribution and its mechanical properties;

- $\quad$ Fiber-matrix interfacial properties: Chemical and frictional bond.

These properties can be adjusted to achieve strain hardening behavior while keeping practical fibers content [2]. To effectively use the combination of all parameters, researchers 
have proposed different criteria and theoretical models for critical volume fraction for any given set of ECC constituents [2-8]. ECC possesses high ductility due to strain hardening characteristics and has the ability of self-healing and crack width control [9]. Due to its excellent properties, it has increased the load-carrying capacity of many structures, especially structures subjected to earthquake and fatigue loading $[10,11]$.

It is very difficult to predict fiber reinforced concrete (FRC) fracture behavior based on its constituents, i.e., whether the concrete will have strain-hardening or undergo strainsoftening. The design procedure for achieving strain-hardening of concrete is based on extensive experimentation. Moreover, the models developed by researchers for finding the critical fiber volume are based on certain factors that need to be found by experiments making this work quite lengthy, time-consuming, and uneconomical [12]. There are no defined guidelines for preparing a mixed design of strain hardening FRC. Consequently, there ought to be a tool to help prepare a mix with higher possibilities of undergoing strain-hardening and predicting its properties.

The development of machine learning (ML) methods has shown promising results in predicting materials properties [12-14]. It can consider complex datasets having multiple inputs and output variables and predict results with high accuracies $[15,16]$. These methods have already been applied to predict compressive strength, tensile strength, and strain capacity of high-performance fiber-reinforced cementitious composites (HPFRCC) [12] using 387 samples. The study by Guo et al. includes the data of HPFRCCs samples with 14 input and 3 output variables that owe the strain-hardening behavior. However, the model has a limitation on applicability only for the HPFRCC samples having strain hardening tendency. Therefore, value addition is required by developing a model with a widened scope of practice over conventional high-performance FRC mixes after requisite training and validation sets for the two streams.

This paper proposes innovation in two areas; the first is related to the functionality and comprehensiveness of the model, which is not just limited to strain-hardening FRCs, and the second is related to the model's accuracy. Firstly, for the first time, data of FRC, ECC, and HPFRCC are collected together. A new output parameter is introduced, which belonged to the failure classification, i.e., fracture behavior. The reason to introduce this variable is to make the model familiar with the basics of post cracking behavior, so it can predict whether the resulting mix would result in strain hardening composite or not. The second is related to performance; the performance parameters achieved are relatively better than the previously made models [12]. There are 438 data samples are cumulatively used to develop the comprehensive model for FRC containing 194 samples [17-35], 231 ECC, and 13 HPFRC [36-98] extracted from published literature. Five ML models were developed. These include artificial neural network (ANN), the support vector machine (SVM), the classification and regression tree (CART), the Gaussian process of regression (GPR), and the extreme gradient boosting tree (XGBoost). As ECC is a new material, the data available in the literature are not significant for ML, and thus, the Generative Adversarial Network (GAN) model is used for data augmentation. A virtual dataset of 1000 samples is successfully extracted by this model and is used for training while the original set is used for testing. The performance-based on this technique is phenomenal. Finally, the accuracy of all models is compared to find the best model.

\section{Methodology}

\subsection{Machine Learning Models}

This section elaborates on the machine learning models used in the research. Five models were used to predict four parameters, out of which three were related to Regression, and one was related to classification. Among the five models, Gaussian Process Regression (GPR) cannot be used for classification rest all can be used for all types of data. Broadly, these models are divided into three categories: (1) Artificial Neural Networks (ANN), (2) Regression Analysis, and (3) Regression Tree analysis. 


\subsubsection{Artificial Neural Networks (ANN)}

ANN is a bio-inspired computational model that works the way human neurons work, which is why it has this name. This model contains three basic parameters (1) Input layer, (2) Output layer, and (3) Hidden layer. However, there are also some other parameters, but they were kept as default. For our problem, parameters for input and output are fixed. The hidden layer is a parameter that depends on data and defines the complexity of the model. The more hidden layers, the better the model can fit. However, it may cause overfitting, a situation in which data fits very well for the training dataset but performs poorly for the testing dataset [99]. Thus, the network was trained for different layers, and the optimum number of hidden layers was found by comparing the RMSE of training and validation datasets. Figure 1a depicts a typical ANN model.

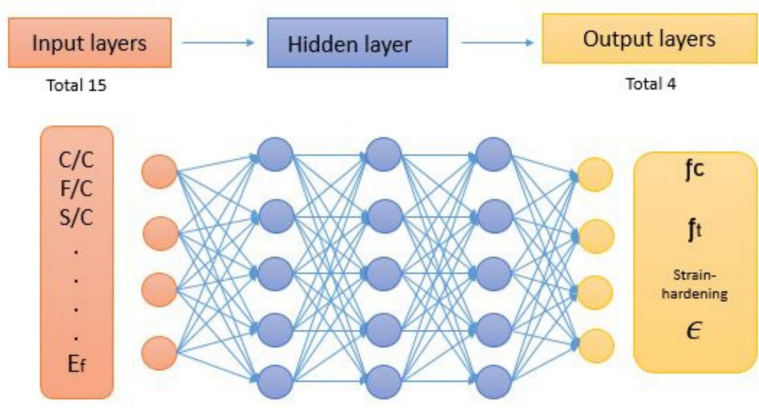

(a)



(b)

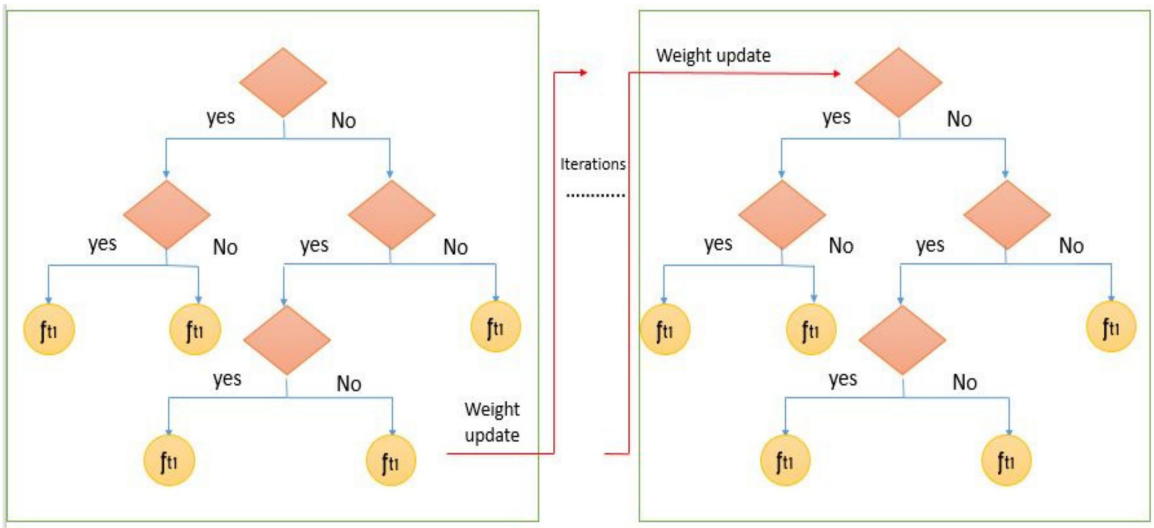

(c)

Figure 1. Machine Learning Models: (a) ANN; (b) CART; (c) XGBoost. $\mathrm{f}_{\mathrm{t}}$ is the Tensile strength; $\mathrm{C} / \mathrm{C}$ is the cement-to-cement Ratio; $\mathrm{F} / \mathrm{C}$ is the Fly ash to cement ratio; $\mathrm{S} / \mathrm{C}$ is the sand to cement ratio; $E_{f}$ is the elastic modulus of fiber; $f_{c}$ is the Compressive Strength; eis the tensile Strain Capacity. 


\subsubsection{Regression Analysis}

This is the most common family of models containing many different types with separate parameters, with the goal being to fit the data as closely as possible [100]. Common regression models include linear regression and polynomial regression.

\subsubsection{Regression Tree Analysis}

Regression Tree is one of the most potent tools of ML for regression analysis. It performs the calculations in a hierarchal (Tree-like) manner. The number of trees is a parameter that defines its complexity; however, the model cannot be made too complex to avoid overfitting [101]. Common Regression Tree models include CART and XGBoost (iterative tree). Figure $1 b, c$ shows typical CART and XGBoost model respectively.

\subsection{Generative Adversarial Network (GAN)}

In addition to the above models, a specialized data augmentation technique known as Generative Adversarial Network (GAN) was used. GAN is a technique used when the available data is not very large, allowing virtual data to increase accuracy by increasing the dataset [14]. Figure 2 show the processing of data to get virtual dataset.

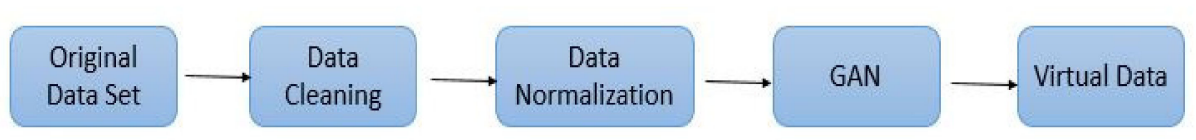

Figure 2. Processing of dataset.

\subsection{Dataset}

\subsubsection{Overview}

For the development of the ML model, a dataset with 19 instances was used, from which 15 are input parameters, and 4 are outputs. Input parameters include matrix constituents and fiber properties as shown in Table 1. To cover a wide range of cement replacement materials, (1) matrix constituent: the cement-to-cement ratio, the fly ash-tocement ratio, the sand-to-cement ratio, the coarse aggregate-to-cement ratio, the limestone powder-to-cement ratio, the slag-to-cement ratio, the silica fume-to-cement ratio, the metakaolin-to-cement ratio, the fiber content, the water-to-binder ratio, and the superplasticizer content was used. Major parameters that define (2) fiber properties are: the fiber length, the fiber diameter, the fiber tensile strength, and the fiber elastic modulus.

Table 1. Input parameters details.

\begin{tabular}{cccccc}
\hline No: & Input Variable & Range & Unit & Mean & Standard Deviation \\
\hline 1 & Cement-to-cement ratio & 1 & 1 & 1 & 0 \\
2 & Fly ash-to-cement ratio & $0-4.4$ & 1 & 0.64 & 0.97 \\
3 & Sand-to-cement ratio & $0-6.5$ & 1 & 1.3 & 0.9 \\
4 & Coarse aggregate-to-cement ratio & $0-7.24$ & 1 & 1.15 & 1.53 \\
5 & Limestone powder-to-cement ratio & $0-6.5$ & 1 & 0.052 & 0.39 \\
6 & Slag-to-cement ratio & $0-4$ & 1 & 0.109 & 0.38 \\
7 & Silica fume-to-cement ratio & $0-0.375$ & 1 & 0.037 & 0.08 \\
8 & Metakaolin-to-cement ratio & $0-0.5$ & 1 & 0.011 & 0.05 \\
9 & Fiber content & $0-7$ & $\%$ & 1.59 & 0.89 \\
10 & Water-to-binder ratio & $0.14-0.99$ & 1 & 0.42 & 0.16 \\
11 & Superplasticizer content. & $0-6$ & $\%$ & 1.1 & 1.5 \\
12 & Fiber length & $0-100$ & $\mathrm{~mm}$ & 16.7 & 12 \\
13 & Fiber diameter & $0-1000$ & $\mu \mathrm{m}$ & 176 & 259 \\
14 & Fiber tensile strength & $0-4475$ & $\mathrm{MPa}$ & 1476 & 800 \\
15 & Fiber elastic modulus & $0-228$ & $\mathrm{GPa}$ & 80.2 & 71 \\
\hline
\end{tabular}


Predicting the fracture response of the material is made possible using the dataset of conventional and HPFRC as well as the ECC samples. If only ECC samples were used to predict properties, there would have been a problem with the model of not differentiating the sample of other types of FRC. The model would have been treating input of any fiber concrete as an ECC and predicting higher values of strains considering strain-hardening. Training ML on the behavior of both FRC and ECC materials was made to overcome this issue. The trained model can predict the post cracking response based on variable differences in FRC and ECC.

The HPFRCCs sample data were included to capture the effect of coarse aggregate addition on the fracture attributes of the matrix. As ECC lacks coarse aggregate compared with FRC, the model might have confused the strain-softening behavior to the presence of coarse aggregates. Thus, HPFRCC data are added to avoid this mishap as it has coarse aggregate and shows stain-hardening simultaneously.

\subsubsection{Dataset Normalization}

The data were collected from literature initially in raw form. Their range was drastically different, e.g., cement content was normally around 1, but other parameters such as fiber diameter or elastic modulus of fiber were in the range of hundreds. Therefore, data normalization was necessary so that the model could predict the sensitivity of each parameter, which ultimately affects the results. Therefore, to keep all the parameters between 0 and 1, the following normalization technique was used. For normalization, Equation (1) was used to keep the data between 0 and 1 .

$$
\mathrm{x} *=\frac{\mathrm{x}-\mathrm{x}(\min )}{\mathrm{x}(\max )-\mathrm{x}(\min )}
$$

$\mathrm{x}$ is any original input parameter; $\mathrm{x}(\mathrm{min})$ is the minimum value of the similar parameter; $x(\max )$ is the maximum value of the parameter; $x$ is the normalized value of the parameter.

\subsubsection{Hyperparameter Tuning}

Hyperparameter tuning is the most crucial parameter of machine learning models. In ANN, it corresponds to the number of hidden layers and learning rate, and in regression tree depends upon the number of branches. A simple iterative technique was used to find the performance of the model by changing the parameters. The best parameter for both training and validation sets was selected to counter underfitting and overfitting.

\subsubsection{Performance Evaluation}

In order to test the performance accuracy of the model, three basic performance parameters were used for regression data to relate the predicted $\left(\mathrm{Y}_{\text {pre }}\right)$ and actual results $\left(Y_{\text {actual }}\right)[102,103]$. These three parameters include (1) root mean squared error (RMSE), (2) coefficient of determination $\left(R^{2}\right)$, and (3) Pearson correlation coefficient (R) as given by Equations (2)-(4).

$$
\begin{gathered}
\text { RMSE }=\sqrt{\frac{1}{n} \cdot \sum_{i=1}^{n}\left(\text { Ypre }- \text { Yactual }^{2}\right.}, \\
R=\frac{\sum_{i}^{n}=1(\text { Ypre }-\overline{\text { Ypre }}) \cdot(\text { Yactual }-\overline{\text { Yactual }})}{\sqrt{\sum_{i}^{\mathrm{n}}=1(\text { Ypre }-\overline{\text { Ypre }})^{2}} \cdot \sqrt{\sum_{i}^{\mathrm{n}}=1(\text { Yactual }-\overline{\text { Yactual }})^{2}}} \\
\mathrm{R}^{2}=\frac{\sum_{\mathrm{i}}^{\mathrm{n}}=1(\text { Ypre }-\overline{\text { Ypre }})}{\sum_{\mathrm{i}}^{\mathrm{n}}=1(\text { Yactual }-\overline{\text { Yactual }})}
\end{gathered}
$$

However, the classification data were evaluated based on fundamental parameters of AUC (Area under Curve), the area under the ROC curve, and accuracy in predicting the data. 


\section{Implementations}

\subsection{Anomalous Data}

Anomalous data are the outlier that can affect the model's accuracy. Data are extracted from already published articles, including the hypothetical trails of different mixes. Fourteen such samples were removed, e.g., mix with $10 \%$ fibers, as it was an outlier, so it was removed. In the same way, reported compressive strength of over $200 \mathrm{MPa}$ was also an outlier; therefore, it was also removed.

\subsection{Hyperparameter Tuning}

Table 2 shows the optimal hyperparameters for different machine learning models used for each output parameter. There are different sorts of interlinking between input and output parameters. Therefore, for better results, each hyperparameter was calculated using the simplified approach of using a loop and finding the optimal combination for which the error is minimal for both training and validation sets, along with keeping a special check on overfitting. Since the numbers of hyperparameters in some models were very high, tuning was done only on some of the hyperparameters, and the rest were taken as default. Table 2 shows Hyperparameters that were optimized. The hyperparameters missing in this table were kept as default. XGBoost showed good results using the default hyperparameters without any tuning.

Table 2. The optimal hyperparameters for ML models.

\begin{tabular}{|c|c|c|c|c|c|c|}
\hline \multirow[b]{2}{*}{ Method } & \multirow[b]{2}{*}{ Hyperparameters } & \multirow[b]{2}{*}{ Range } & \multicolumn{4}{|c|}{ Optimal Value for Different Parameters } \\
\hline & & & $\begin{array}{l}\text { Compressive } \\
\text { Strength }\end{array}$ & Tensile Strength & $\begin{array}{c}\text { Strain- } \\
\text { Hardening }\end{array}$ & $\begin{array}{c}\text { Tensile Strain } \\
\text { Capacity }\end{array}$ \\
\hline ANN & Hidden layer size & $1-100$ & 55 & 64 & 65 & 68 \\
\hline \multirow{3}{*}{ SVM } & $\mathrm{C}$ & $1-20$ & 10 & 6 & 12 & 9 \\
\hline & Gamma & $0.1-1$ & 0.4 & 0.3 & 0.7 & 0.6 \\
\hline & Epsilon & $0.1-2$ & 0.1 & 0.1 & 0.1 & 0.1 \\
\hline \multirow{2}{*}{ CART } & Maximum depth & $2-10$ & 2 & 5 & 2 & 4 \\
\hline & Minimum samples leaf & $2-10$ & 2 & 2 & 2 & 2 \\
\hline \multirow{2}{*}{ GPR } & Kernel Scale & $0.001-1$ & 0.024 & 0.034 & 0.028 & 0.022 \\
\hline & Sigma & $0.0001-254$ & 0.0054 & 0.06 & 0.00326 & 0.00125 \\
\hline
\end{tabular}

\subsection{Training Process}

For the training process, all the optimal hyperparameters listed in Table 2 were used to train the machine learning model. Special attention was given to ensure the model neither be under-fitted nor overfit. The training process was done, and the performance of each model was calculated separately for the training and testing dataset as per parameters defined in Section 2.3.4. Figure 3 show the approach employed for training the model.

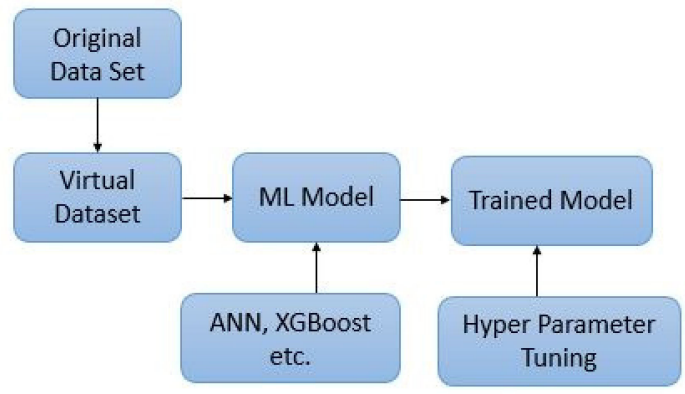

Figure 3. Training of model. 


\section{Results and Discussions}

\subsection{Predicted Results and Discussions}

Based on above mentioned trained models, compressive strength, tensile strength, tensile strain, and post cracking behavior (whether strain hardening would occur or not) can be predicted. Tables 3-5 compare actual vs. predicted results of the defined output parameters. The prediction accuracy was measured in terms of $\mathrm{R}^{2}$ value and $\mathrm{R}$-value. Its larger value corresponds to high prediction accuracy, while in the case of RMSE value, a low value indicates high accuracy. For post cracking behavior AUC and accuracy are used. Their higher value indicates higher prediction accuracy.

Table 3. Comparison of predicted and actual values of mechanical properties.
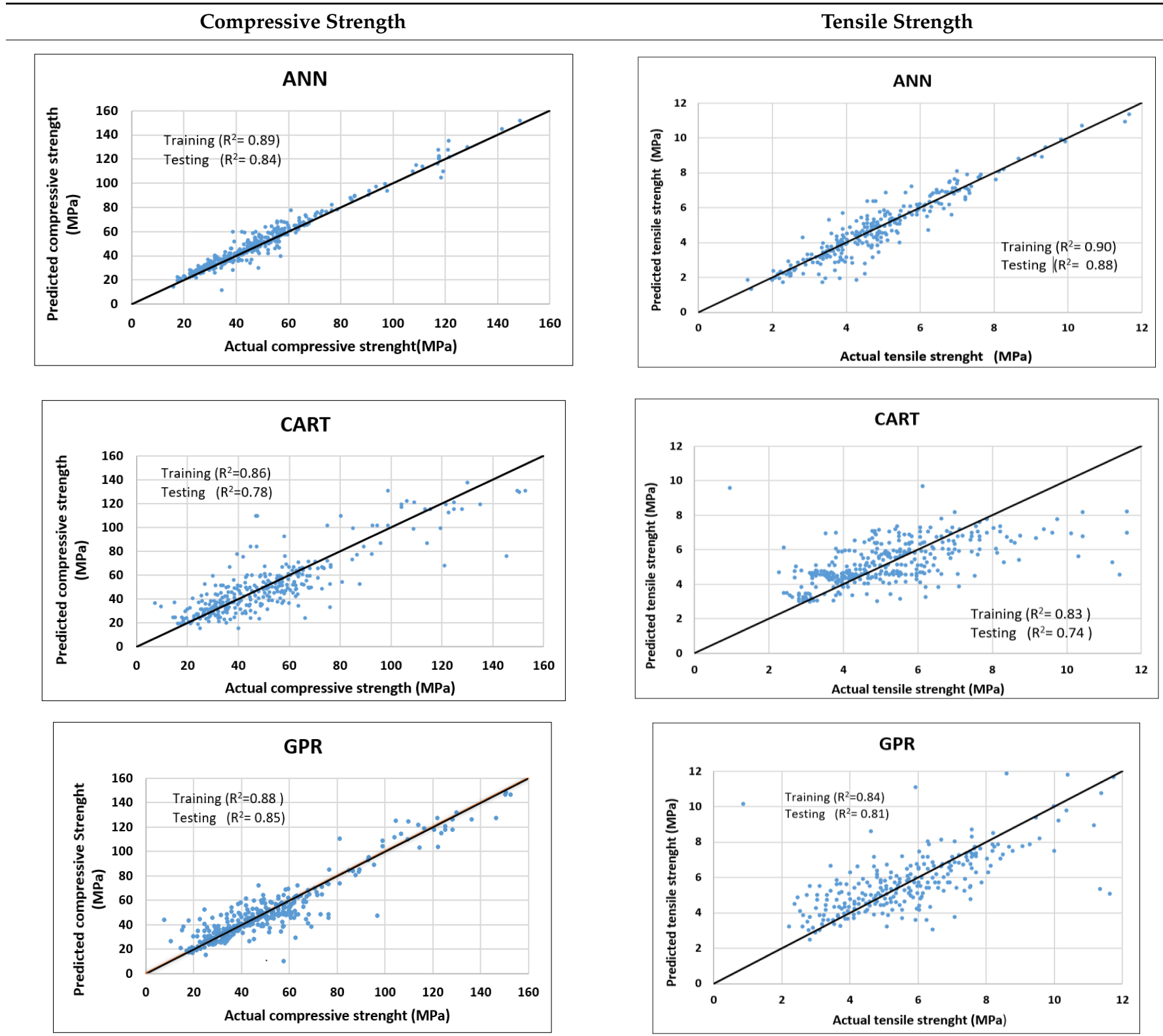
Table 3. Cont.

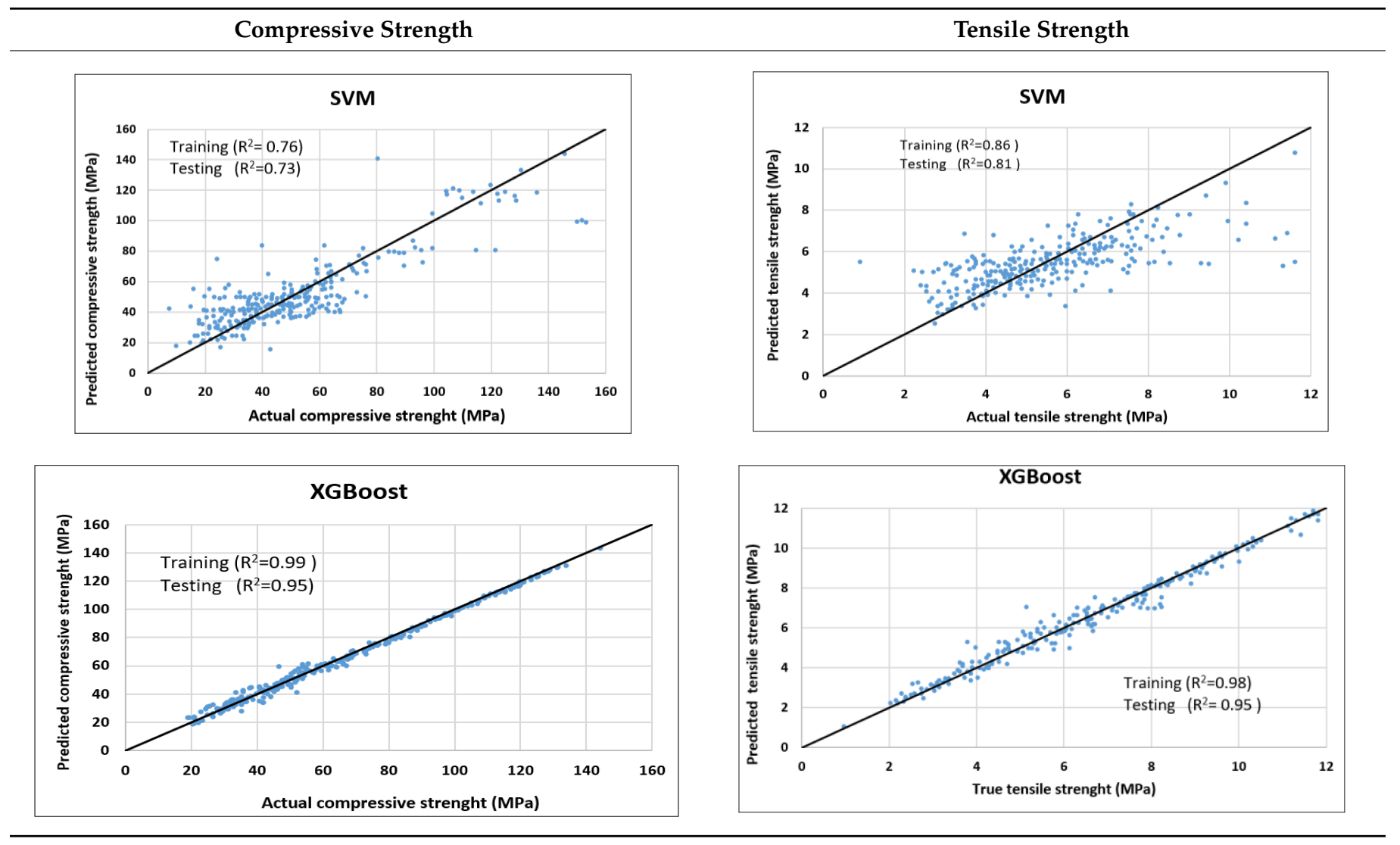

Table 4. Comparison of predicted and actual values of ductility properties.

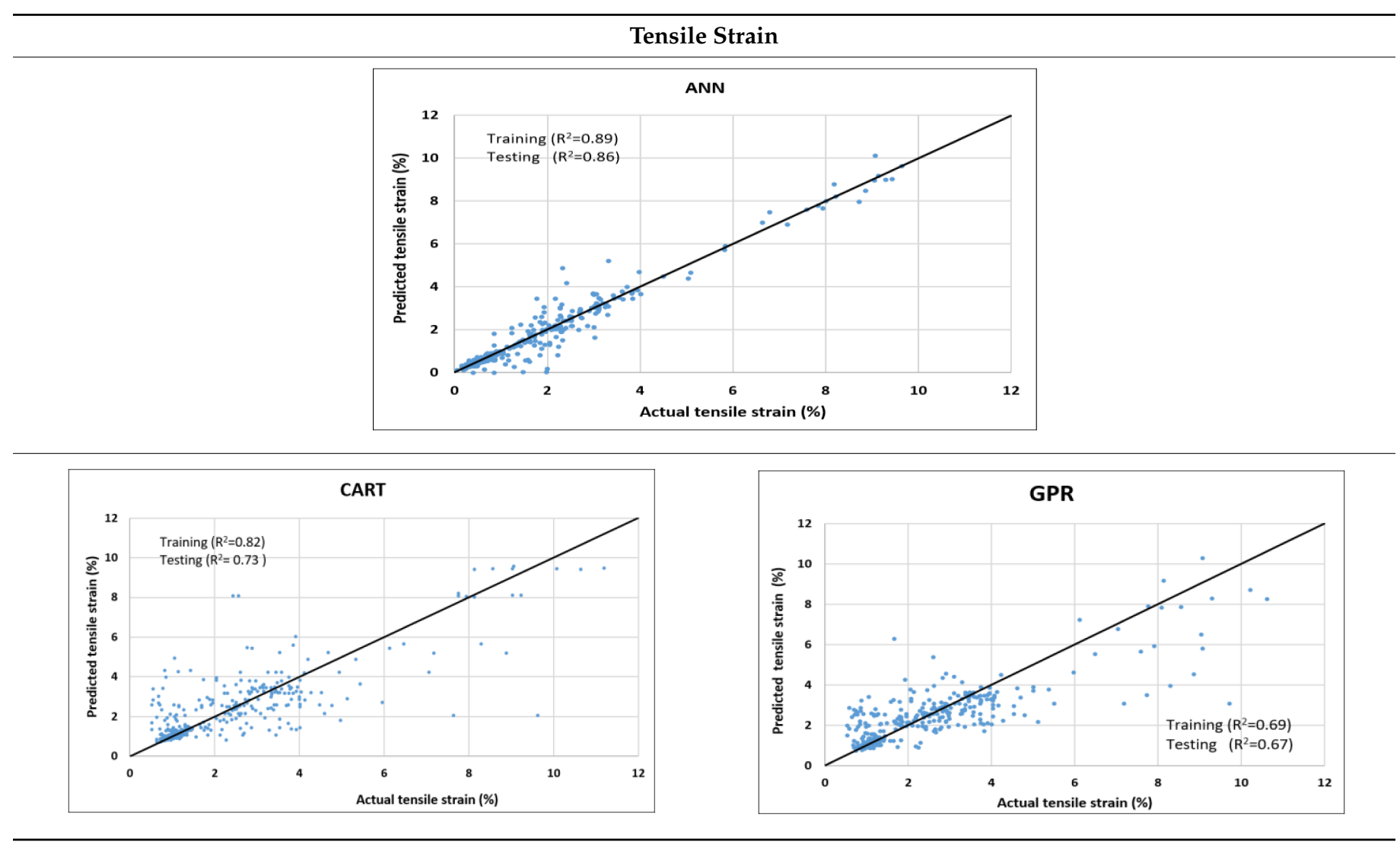


Table 4. Cont

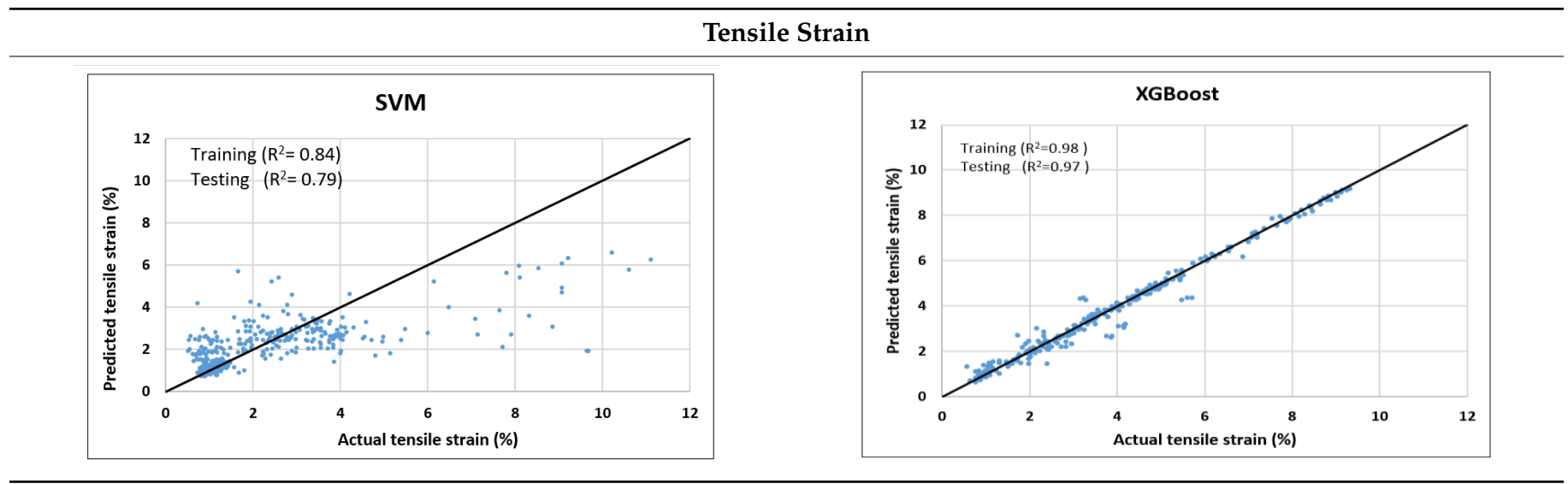

Table 5. AUC and Confusion matrix for predicting Post-cracking response.

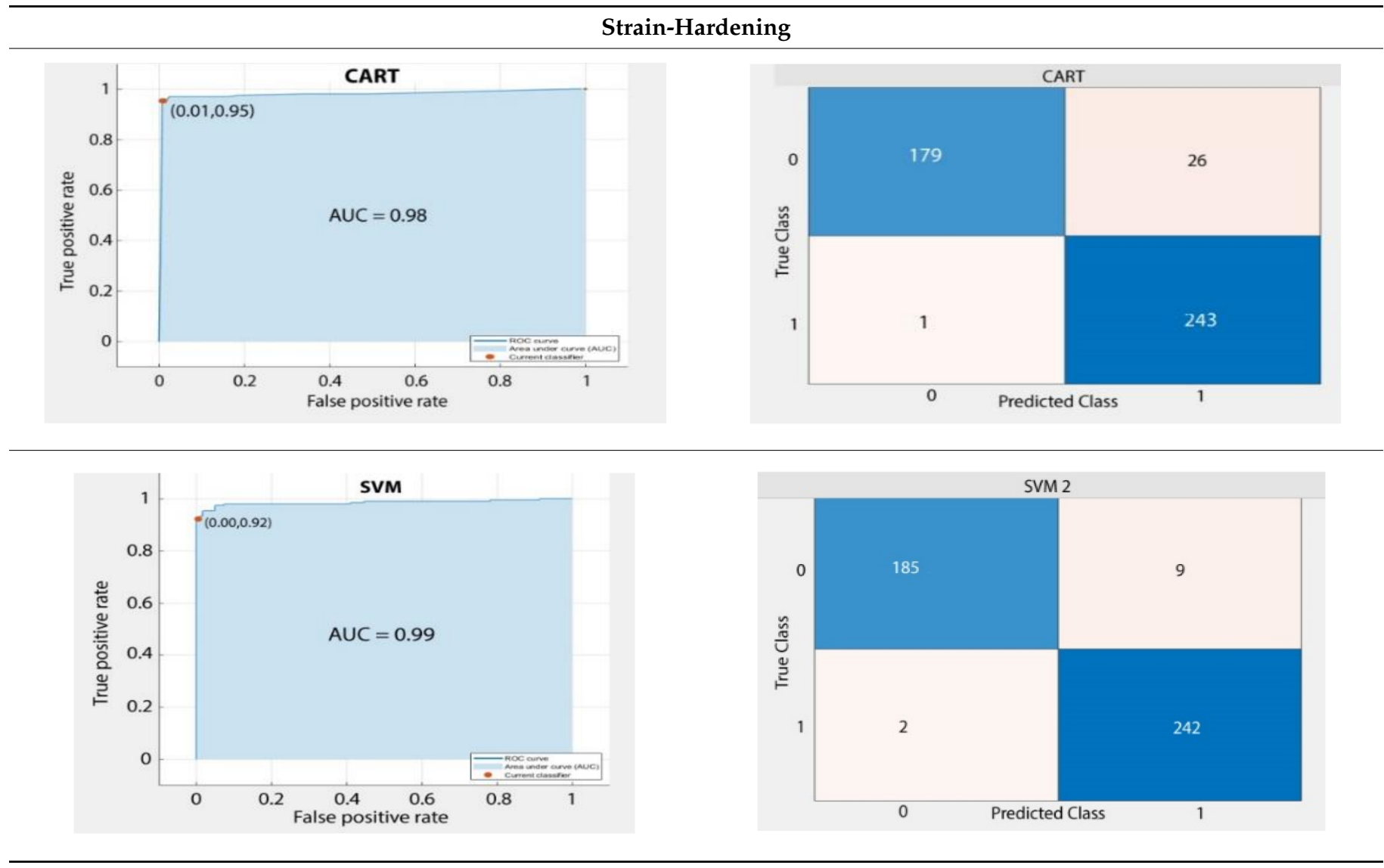

The performance of each model is summarized in Table 6. The performance of the models was evaluated as per Section 2.3.4. The results of both testing and training data sets were compared to avoid under fitting and overfitting. Among all models, the XGBoost method shows the best accuracy for all the output parameters followed by ANN, GPR, CART, and SVM. This model gives RMSE for a training set of compressive strength, tensile strength, and ductility as $1.59,0.2$, and 0.163 , respectively, while for the testing set RMSE is $2.35,0.31$, and 0.18 , respectively, which was more accurate compared to the previous models [12] in which RMSE for a training set of compressive strength, tensile strength, and ductility as $2.5,0.36$, and 0.25 , respectively, while for the testing set RMSE is 6.75 , 0.774 , and 0.785 , respectively. The value of $R^{2}$ for XGBoost was $0.99,0.98$, and 0.98 for 
compressive strength, tensile strength, and tensile strain, respectively, for training while $0.95,0.95$, and 0.97 for testing. XGBoost was able to classify the fracture behavior of the samples more accurately compared to other models. Its accuracy for classification was $98.5 \%$ and $98.4 \%$ for training and testing, respectively. The high accuracy of XGBoost is due to its iterative architecture, as shown in Figure 1c, which creates a better relationship between input and output parameters. Complete working process of predictive model is shown in Figure 4.

Table 6. Evaluation of predicted results.

\begin{tabular}{|c|c|c|c|c|c|c|}
\hline Model & Set & Evaluation & $\begin{array}{c}\text { Compressive } \\
\text { Strength }\end{array}$ & $\begin{array}{c}\text { Tensile } \\
\text { Strength }\end{array}$ & $\begin{array}{c}\text { Strain- } \\
\text { Hardening }\end{array}$ & $\begin{array}{c}\text { Tensile Strain } \\
\text { Capacity }\end{array}$ \\
\hline \multirow{10}{*}{ ANN } & \multirow{5}{*}{ Training } & RMSE & 5.7 & 0.7549 & - & 0.7189 \\
\hline & & $\mathrm{R}^{2}$ & 0.893 & 0.902 & - & 0.899 \\
\hline & & $\mathrm{R}$ & 0.94 & 0.941 & - & 0.93 \\
\hline & & AUC & - & - & 0.98 & - \\
\hline & & Accuracy & - & - & $96.3 \%$ & - \\
\hline & \multirow{5}{*}{ Testing } & RMSE & 7.3 & 1.038 & - & 0.7726 \\
\hline & & $\mathrm{R}^{2}$ & 0.84 & 0.885 & - & 0.86 \\
\hline & & $\mathrm{R}$ & 0.92 & 0.937 & - & 0.91 \\
\hline & & AUC & - & - & 0.97 & - \\
\hline & & Accuracy & - & - & $94 \%$ & - \\
\hline \multirow{10}{*}{ SVM } & \multirow{5}{*}{ Training } & RMSE & 12.05 & 1.4 & - & 1.3 \\
\hline & & $\mathrm{R}^{2}$ & 0.76 & 0.86 & - & 0.84 \\
\hline & & $\mathrm{R}$ & 0.88 & 0.927 & - & 0.9 \\
\hline & & AUC & - & - & 0.98 & - \\
\hline & & Accuracy & - & - & $97.5 \%$ & - \\
\hline & \multirow{5}{*}{ Testing } & RMSE & 12.49 & 1.8 & - & 1.44 \\
\hline & & $\mathrm{R}^{2}$ & 0.73 & 0.81 & - & 0.79 \\
\hline & & $\mathrm{R}$ & 0.84 & 0.9 & - & 0.87 \\
\hline & & AUC & - & - & 0.96 & - \\
\hline & & Accuracy & - & - & $97 \%$ & - \\
\hline \multirow{10}{*}{ CART } & \multirow{5}{*}{ Training } & RMSE & 6.025 & 1.8 & - & 1.1 \\
\hline & & $\mathrm{R}^{2}$ & 0.868 & 0.83 & - & 0.82 \\
\hline & & $\mathrm{R}$ & 0.91 & 0.9 & - & 0.89 \\
\hline & & AUC & - & - & 0.98 & - \\
\hline & & Accuracy & - & - & $94.67 \%$ & - \\
\hline & \multirow{5}{*}{ Testing } & RMSE & 11.97 & 1.97 & - & 1.357 \\
\hline & & $\mathrm{R}^{2}$ & 0.78 & 0.74 & - & 0.73 \\
\hline & & $\mathrm{R}$ & 0.87 & 0.855 & - & 0.85 \\
\hline & & AUC & - & - & 0.95 & - \\
\hline & & Accuracy & - & - & $93 \%$ & - \\
\hline \multirow{10}{*}{ XGBoost } & \multirow{5}{*}{ Training } & RMSE & 1.59 & 0.2 & - & 0.163 \\
\hline & & $\mathrm{R}^{2}$ & 0.99 & 0.983 & - & 0.98 \\
\hline & & $\mathrm{R}$ & 0.995 & 0.9918 & - & 0.9927 \\
\hline & & AUC & - & - & 0.998 & - \\
\hline & & Accuracy & - & - & $98.5 \%$ & - \\
\hline & \multirow{5}{*}{ Testing } & RMSE & 2.35 & 0.31 & - & 0.18 \\
\hline & & $\mathrm{R}^{2}$ & 0.95 & 0.95 & - & 0.974 \\
\hline & & $\mathrm{R}$ & 0.97 & 0.97 & - & 0.991 \\
\hline & & AUC & - & - & 0.99 & - \\
\hline & & Accuracy & - & - & $98.4 \%$ & - \\
\hline \multirow{6}{*}{ GPR } & \multirow{3}{*}{ Training } & RMSE & 8.6 & 1.1 & - & 1.007 \\
\hline & & $\mathrm{R}^{2}$ & 0.88 & 0.84 & - & 0.69 \\
\hline & & $\mathrm{R}$ & 0.92 & 0.89 & - & 0.81 \\
\hline & \multirow{3}{*}{ Testing } & RMSE & 9.1 & 1.37 & - & 1.16 \\
\hline & & $\mathrm{R}^{2}$ & 0.85 & 0.81 & - & 0.67 \\
\hline & & $\mathrm{R}$ & 0.89 & 0.86 & - & 0.8 \\
\hline
\end{tabular}




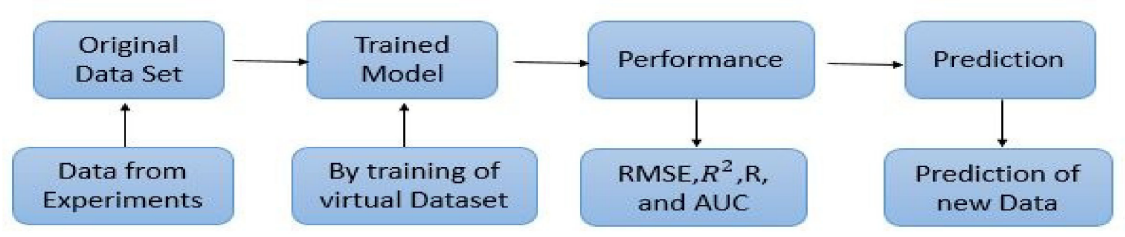

Figure 4. Working of predictive model.

\subsection{Validation of Predictive Models}

It is clear from Table 6 that the XGBoost model has the maximum accuracy compared to the other models. Thus, it was used to predict compressive strength, tensile strength, tensile strain, and the post-cracking response of samples that are not included in any dataset (neither in original nor in virtual). The model was practiced for validation by published experiments' data. Samples with one varying parameter were checked. Two types of samples with varying percentage content of flyash and fiber content were tested. Figure 5 shows the comparison of actual v/s predicted properties of samples. Results reveal that XGBoost is accurate in predicted values, and classification made by the model about post cracking behavior is also $100 \%$ true.

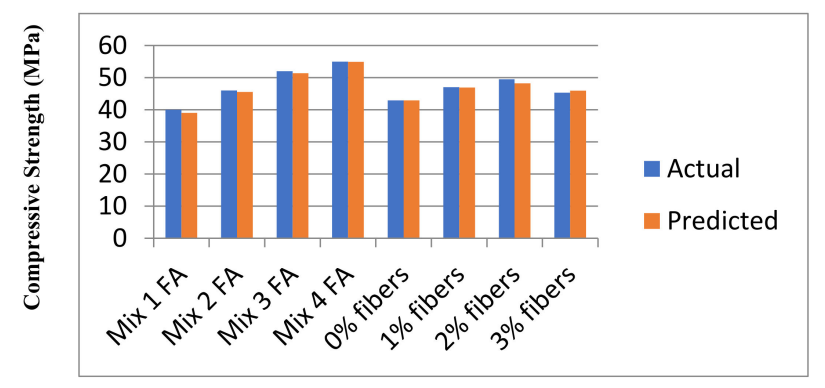

(a)

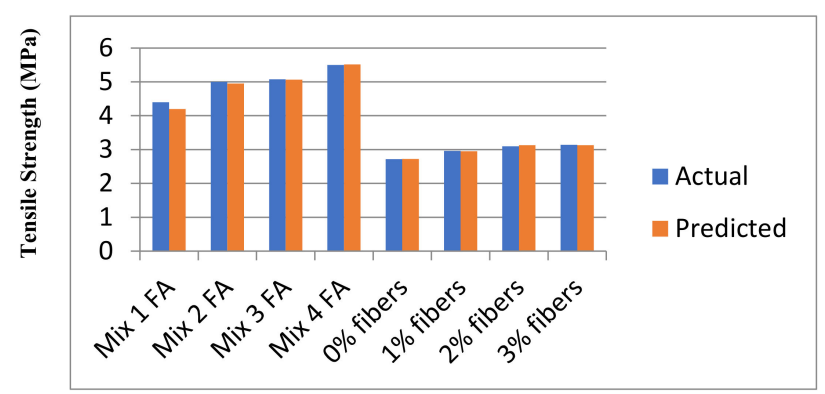

(b)

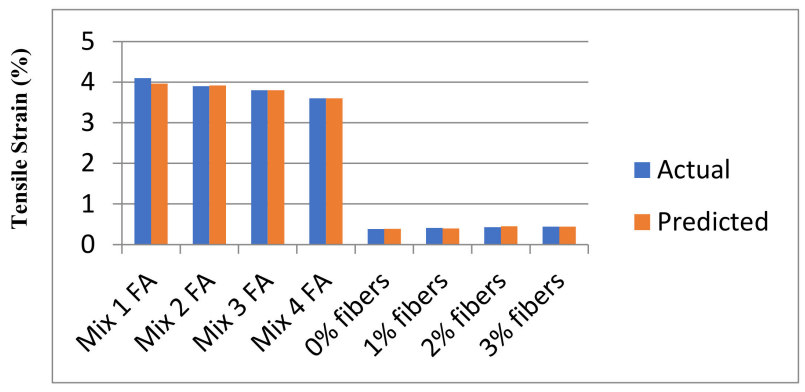

(c)

Figure 5. Comparison of prediction using XGBoost against the test results (a): Compressive Strength; (b) Tensile Strength; (c) Tensile strain. 


\section{Conclusions and Recommendations}

This research was able to develop a new way to predict fracture properties (i.e., Mechanical properties, ductility, and the post-cracking response) of FRC, using the aid of machine learning. Five models were developed to predict four outputs with 15 input parameters of FRC. The performance of each model was evaluated, and from those following conclusions were made:

- The predictive models are accurate enough to replace the extensive experimentation trails required for optimizing FRC according to desired needs.

- These models can be effectively used to bifurcate fracture behavior as strain hardening or softening based on selected inputs as they are well trained for both types of behavior. XGBoost model shows $98.4 \%$ accuracy in segregating the fracture response of fiberreinforced matrices.

- The above-proposed models can realistically be used to predict mechanical properties, ductility, and post-cracking behavior of both the traditional and high-performance FRC. Among all models, the XGBoost model shows the best accuracy for all the output parameters. This model gives RMSE for a training set of compressive strength, tensile strength, and ductility as $1.59,0.2$, and 0.163 , respectively, while for the testing set RMSE is $2.35,0.31$, and 0.18 , respectively. These performance indicators of RMSE were more accurate than previously implemented models [12].

- GAN was used to successfully produce a virtual dataset of 1000 samples using the original dataset. This virtual dataset further increased the accuracy of the models.

- These models can also be optimized in a way to make the mix economic with improved mechanical properties along with minimizing the environmental impacts (e.g., carbon footprint and reuse of waste products)

Future research is needed to find out other parameters and their dependence on different important parameters of FRC, e.g., fresh properties, durability properties, use of other types of cement, or incorporating the packing density concept for high strength concrete. More research is also needed using these models for other types of specialpurpose concretes.

Author Contributions: Conceptualization, S.A.K.; methodology, S.A.K. and T.A.; software, S.A.K.; validation, R.A.K.; formal analysis, T.A., R.A.K. and S.A.K.; investigation, T.A. and S.A.K.; resources, S.M.A. and S.; data curation S., S.M.A., T.A. and S.A.K.; writing—original draft preparation, S.A.K. and T.A.; writing-review and editing, R.A.K., S.A.K. and T.A.; supervision, R.A.K.; project administration, S.A.K., T.A., R.A.K. and S.; All authors have read and agreed to the published version of the manuscript.

Funding: This research received no external funding.

Institutional Review Board Statement: Not applicable.

Informed Consent Statement: Not applicable.

Data Availability Statement: Data is contained within the article.

Acknowledgments: Authors would like to say special thanks to Muhammad Riyyan Khan (Khan.riyyan@yahoo.com) and Muhammad Umar Javed (mjaved.bscs18seecs@seecs.edu.pk) for useful discussion on the Implementation of ML models and would also like to thank Sadia Arshad and Hammad Anis Khan for guidance on the article writing and its formatting.

Conflicts of Interest: The authors declare no conflict of interest. 


$\begin{array}{ll}\text { Abbreviations } \\ \text { FRC } & \text { Fiber Reinforced Concrete } \\ \text { ECC } & \text { Engineered Cementitious Concrete } \\ \text { HPFRCCs } & \text { High Performance Fiber Reinforced Cementitious Composites } \\ \text { ANN } & \text { Artificial Neural Network } \\ \text { SVM } & \text { Support Vector Machine } \\ \text { GPR } & \text { Gaussian Process of Regression } \\ \text { XGBoost } & \text { Extreme Gradient Boosting Tree } \\ \text { CART } & \text { Classification and Regression Tree } \\ \text { GAN } & \text { Generative Adversarial Network } \\ \text { ML } & \text { Machine Learning } \\ \text { RMSE } & \text { Root Mean Squared Error } \\ \text { AUC } & \text { Area under Curve } \\ \text { R }^{2} & \text { Coefficient of determination } \\ \text { R } & \text { Pearson correlation coefficient }\end{array}$

\section{References}

1. Romualdi, J.P.; Batson, G.B. Mechanics of Crack Arrest in Concrete. J. Eng. Mech. Div. 1963, 89, 147-168. [CrossRef]

2. Li, V.; Stang, H.; Krenchel, H. Micromechanics of crack bridging in fibre-reinforced concrete. Mater. Struct. 1993, 26, 486-494. [CrossRef]

3. Li, V.C.; Leung, C.K. Steady-state and Multiple Creaking of Short random fiber composites. J. Eng. Mech. 1992, 118, 2246-2264. [CrossRef]

4. Li, V.C. From micromechanics to structural engineering-The design of cementitious composites for civi for civil applications. Structrual Eng. Earthq. Eng. 1993, 10,37s-48s.

5. Li, V.C.; Mishra, D.K.; Wu, H.-C. Matrix Design for Pseudo Strain-Hardening Fiber Reinforced Cementitious Composites. Mater. Struct. 1995, 28, 586-595. [CrossRef]

6. Yang, C.C.; Mura, T.; Shah, S.P. Micromechanical Theory and Uniaxial Tensile Tests of Fiber Reinforced Cement Composites. 2015. Available online: http:/ /journals.cambridge.org (accessed on 1 May 2021).

7. McCartney, L. Mechanics of Matrix Cracking in Brittle-Matrix Fibre-Reinforced Composites. 1987. Available online: https://www. jstor.org/stable/2398127 (accessed on 1 May 2021).

8. Leung, C.K. Design criteria for pseudoductile fiber-reinforced composites. J. Eng. Mech. 1996, 122, 10-18. [CrossRef]

9. Liu, H.; Zhang, Q.; Gu, C.; Su, H.; Li, V. Influence of microcrack self-healing behavior on the permeability of Engineered Cementitious Composites. Cem. Concr. Compos. 2017, 82, 14-22. [CrossRef]

10. Li, X.; Wang, J.; Bao, Y.; Chen, G. Cyclic behavior of damaged reinforced concrete columns repaired with high-performance fiber-reinforced cementitious composite. Eng. Struct. 2017, 136, 26-35. [CrossRef]

11. Fukuyama, H. Application of High Performance Fiber Reinforced Cementitious Composites for Damage Mitigation of Building Structures Case study on Damage Mitigation of RC Buildings with Soft First Story. J. Adv. Concr. Technol. 2006, 4, 35-44. [CrossRef]

12. Guo, P.; Meng, W.; Xu, M.; Li, V.; Bao, Y. Predicting Mechanical Properties of High-Performance Fiber-Reinforced Cementitious Composites by Integrating Micromechanics and Machine Learning. Materials 2021, 14, 3143. [CrossRef]

13. Prasad, B.R.; Eskandari, H.; Reddy, B.V. Prediction of compressive strength of SCC and HPC with high volume fly ash using ANN. Constr. Build. Mater. 2009, 23, 117-128. [CrossRef]

14. Marani, A.; Jamali, A.; Nehdi, M.L. Predicting Ultra-High-Performance Concrete Compressive Strength Using Tabular Generative Adversarial Networks. Materials 2020, 13, 4757. [CrossRef]

15. Abu Yaman, M.; Elaty, M.A.; Taman, M. Predicting the ingredients of self compacting concrete using artificial neural network. Alex. Eng. J. 2017, 56, 523-532. [CrossRef]

16. Akande, K.O.; Owolabi, T.O.; Twaha, S.; Olatunji, S. Performance Comparison of SVM and ANN in Predicting Compressive Strength of Concrete. IOSR J. Comput. Eng. 2014, 16, 88-94. [CrossRef]

17. Dhanapal, J.; Jeyaprakash, S. Mechanical properties of mixed steel fiber reinforced concrete with the combination of micro and macro steel fibers. Struct. Concr. 2020, 21, 458-467. [CrossRef]

18. Loh, Z.P.; Mo, K.H.; Tan, C.G.; Yeo, S.H. Mechanical characteristics and flexural behaviour of fibre-reinforced cementitious composite containing PVA and basalt fibres. Sadhana 2019, 44, 98. [CrossRef]

19. Bagherzadeh, R.; Pakravan, H.; Sadeghi, A.-H.; Latifi, M.; Merati, A.A. An Investigation on Adding Polypropylene Fibers to Reinforce Lightweight Cement Composites (LWC). J. Eng. Fibers Fabr. 2012, 7, 1147. [CrossRef]

20. Abbass, A.; Abid, S.; Özakça, M. Experimental Investigation on the Effect of Steel Fibers on the Flexural Behavior and Ductility of High-Strength Concrete Hollow Beams. Adv. Civ. Eng. 2019, 2019, 245. [CrossRef]

21. Wishwesh, K.; Anand, K.B. PVA Fiber-Fly Ash Cementitious Composite: Assessment of Mechanical Properties. 2017. Available online: http:/ / iaeme.com (accessed on 5 June 2021).

22. Lu, C. Mechanical Properties of Polypropylene Fiber Reinforced Concrete Pavement. Adv. Mater. Res. 2013, 739, 264-267. [CrossRef]

23. Liu, F.; Xu, K.; Ding, W.; Qiao, Y.; Wang, L. Microstructural characteristics and their impact on mechanical properties of steel-PVA fiber reinforced concrete. Cem. Concr. Compos. 2021, 123, 104196. [CrossRef] 
24. Zheng, Y.; Wu, X.; He, G.; Shang, Q.; Xu, J.; Sun, Y. Mechanical Properties of Steel Fiber-Reinforced Concrete by Vibratory Mixing Technology. Adv. Civ. Eng. 2018, 2018, 5715. [CrossRef]

25. Babaie, R.; Abolfazli, M.; Fahimifar, A. Mechanical properties of steel and polymer fiber reinforced concrete. J. Mech. Behav. Mater. 2019, 28, 119-134. [CrossRef]

26. Li, F.Y.; Cao, C.Y.; Cui, Y.X.; Wu, P.F. Experimental Study of the Basic Mechanical Properties of Directionally Distributed Steel Fibre-Reinforced Concrete. Adv. Mater. Sci. Eng. 2018, 2018, 1-11. [CrossRef]

27. Yao, Z.; Li, X.; Fu, C.; Xue, W. Mechanical Properties of Polypropylene Macrofiber-Reinforced Concrete. Adv. Mater. Sci. Eng. 2019, 2019, 214. [CrossRef]

28. Singh, S.P. Investigation on the Strength and Flexural Toughness of Hybrid Fibre Reinforced Concrete. In Brittle Matrix Composites 9; Elsevier: Amsterdam, The Netherlands, 2009; pp. 91-100. [CrossRef]

29. Çavdar, A. A study on the effects of high temperature on mechanical properties of fiber reinforced cementitious composites. Compos. Part B Eng. 2012, 43, 2452-2463. [CrossRef]

30. Vafaei, D.; Hassanli, R.; Ma, X.; Duan, J.; Zhuge, Y. Sorptivity and mechanical properties of fiber-reinforced concrete made with seawater and dredged sea-sand. Constr. Build. Mater. 2021, 270, 121436. [CrossRef]

31. Ede, A.N.; Ige, A.O. Optimal Polypropylene Fiber Content for Improved Compressive and Flexural Strength of Concrete. IOSR J. Mech. Civ. Eng. 2014, 11, 129-135.

32. Zeyad, A.; Saba, A.M.; Shathly, A.B.; Alfaufy, T.H. Influence of steel fiber content on fresh and hardened properties of selfcompacting concrete. AIP Conf. Proc. 2018, 2020, 20033. [CrossRef]

33. Thomas, J.; Ramaswamy, A. Mechanical Properties of Steel Fiber-Reinforced Concrete. J. Mater. Civ. Eng. 2007, 19, 385-392. [CrossRef]

34. Leung, C.K.; Lai, R.; Lee, A.Y. Properties of wet-mixed fiber reinforced shotcrete and fiber reinforced concrete with similar composition. Cem. Concr. Res. 2005, 35, 788-795. [CrossRef]

35. Yao, W.; Li, J.; Wu, K. Mechanical properties of hybrid fiber-reinforced concrete at low fiber volume fraction. Cem. Concr. Res. 2003, 33, 27-30. [CrossRef]

36. Hajj, E.Y.; Sanders, D.H.; Weitzel, N.D. Development of Specifications for Engineered Cementitious Composites for Use in Bridge Deck Overlays. Cem. Concr. Res. 2016, 14, 456.

37. Yu, J.; Wu, H.-L.; Leung, C.K. Feasibility of using ultrahigh-volume limestone-calcined clay blend to develop sustainable medium-strength Engineered Cementitious Composites (ECC). J. Clean. Prod. 2020, 262, 121343. [CrossRef]

38. Li, M.; Li, V. High-Early-Strength ECC for Rapid Durable Repair-Material Properties. Available online: https://www.researchgate. net/publication/280231620 (accessed on 5 June 2021).

39. Ma, H.; Qian, S.; Zhang, Z.; Lin, Z.; Li, V.C. Tailoring Engineered Cementitious Composites with local ingredients. Constr. Build. Mater. 2015, 101, 584-595. [CrossRef]

40. Li, X.; Yang, X.; Ding, Z.; Du, X.; Wen, J. ECC Design Based on Uniform Design Test Method and Alternating Conditional Expectation. Math. Probl. Eng. 2019, 2019, 9575897. [CrossRef]

41. Li, V.C. Engineered Cementitious Composites (ECC)-Material, Structural, and Durability Performance. In Concrete Construction Engineering Handbook; Taylor \& Francis Group, LLC: London, UK, 2008.

42. Huang, B.-T.; Weng, K.-F.; Zhu, J.-X.; Xiang, Y.; Dai, J.-G.; Li, V.C. Engineered/strain-hardening cementitious composites (ECC/SHCC) with an ultra-high compressive strength over $210 \mathrm{MPa}$. Compos. Commun. 2021, 26, 100775. [CrossRef]

43. Yu, K.; Zhu, W.; Ding, Y.; Lu, Z.-D.; Yu, J.-T.; Xiao, J.-Z. Micro-structural and mechanical properties of ultra-high performance engineered cementitious composites (UHP-ECC) incorporation of recycled fine powder (RFP). Cem. Concr. Res. 2019, 124, 105813. [CrossRef]

44. Ma, H.; Qian, S.; Li, V.C. Influence of fly ash type on mechanical properties and self-healing behavior of Engineered Cementitious Composite (ECC). Cem. Concr. Res. 2016, 11, 209. [CrossRef]

45. Xu, M.; Clack, H.; Xia, T.; Bao, Y.; Wu, K.; Shi, H.; Li, V. Effect of TiO2 and fly ash on photocatalytic NOx abatement of engineered cementitious composites. Constr. Build. Mater. 2020, 236, 117559. [CrossRef]

46. Xu, M.; Yu, J.; Zhou, J.; Bao, Y.; Li, V.C. Effect of curing relative humidity on mechanical properties of engineered cementitious composites at multiple scales. Constr. Build. Mater. 2021, 284, 122834. [CrossRef]

47. Yao, Q.; Li, Z.; Lu, C.; Peng, L.; Luo, Y.; Teng, X. Development of Engineered Cementitious Composites Using Sea Sand and Metakaolin. Front. Mater. 2021, 8, 1872. [CrossRef]

48. Yang, E.-H.; Li, V. Tailoring engineered cementitious composites for impact resistance. Cem. Concr. Res. 2012, 42, 1066-1071. [CrossRef]

49. Halvaei, M.; Jamshidi, M. The Effect of Nylon Fibers on Mechanical Properties of Engineered Cementitious Composites (ECCs) Preparation and Characterization of Chitosan/Sericin Nanoweb View Project Evaluating Piezoelectric Performance of PVDF Composite Nanofibers Pressure Sensor with Metal Nanoparticle View Project. 2013. Available online: https://www.researchgate. net/publication/262802066 (accessed on 5 June 2021).

50. Bins, S.R.; Kumar, C.S.; Togi, S.; George, M. A Study of Engineered Cementitious Composites by Investigating its Compressive and Flexural Strength. Cem. Concr. Res. 2014, 11, 531950. [CrossRef]

51. Lin, J.-X.; Song, Y.; Xie, Z.-H.; Guo, Y.-C.; Yuan, B.; Zeng, J.-J.; Wei, X. Static and dynamic mechanical behavior of engineered cementitious composites with PP and PVA fibers. J. Build. Eng. 2020, 29, 101097. [CrossRef]

52. Rafiei, P.; Shokravi, H.; Mohammadyan-Yasouj, S.; Koloor, S.; Petrů, M. Temperature Impact on Engineered Cementitious Composite Containing Basalt Fibers. Appl. Sci. 2021, 11, 6848. [CrossRef] 
53. Sutrisno, W.; Komara, I.; Tambusay, A.; Suprobo, P. Beam-to-Column Connections for Medium-Rise Precast Reinforced Concrete SMRF with-L and-U Shaped Beam Reinforcement Anchored Outside The Panel View Project Genetic Algorithm and SAP2000 View Project Indra Komara Institut Teknologi Sepuluh Nopember Engineered Cementitious Compositeas An Innovative Durable Material: A Review. 2019. Available online: www.arpnjournals.com (accessed on 5 June 2021).

54. Sherir, M.A.; Hossain, K.M.; Lachemi, M. Fresh state, mechanical \& durability properties of strain hardening cementitious composite produced with locally available aggregates and high volume of fly ash. Constr. Build. Mater. 2018, 189, 253-264. [CrossRef]

55. Khan, S.W.; Shahzada, K.; Kamal, M.; Khan, S.W.; Alam, M. Experimental Investigation of the Mechanical Properties of Engineered Cementitious Composites (ECC) Intelligent Disaster Management in Pakistan View Project Improvement of Concrete Shielding to Nuclear Radiation Using Barite View Project Experimental Investigation of the Mechanical Properties of Engineered Cementitious Composites (ECC). 2016. Available online: https:/ / www.researchgate.net/publication/308694013 (accessed on 5 June 2021).

56. Interface Tailoring for Strain-Hardening PVA-ECC. 2011. Available online: https://www.researchgate.net/publication/280224066 (accessed on 5 June 2021).

57. Yu, K.; Wang, Y.; Yu, J.; Xu, S. A strain-hardening cementitious composites with the tensile capacity up to $8 \%$. Constr. Build. Mater. 2017, 137, 410-419. [CrossRef]

58. Zhu, Y.; Zhang, Z.; Yang, Y.; Yao, Y. Measurement and correlation of ductility and compressive strength for engineered cementitious composites (ECC) produced by binary and ternary systems of binder materials: Fly ash, slag, silica fume and cement. Constr. Build. Mater. 2014, 68, 192-198. [CrossRef]

59. Wang, S.; Li, V.C. Lightweight engineered cementitious composites (ECC). In International Workshop High Performance Fiber Reinforced Cement Composites, 2nd ed.; RILEM Publications SARL: Paris, France, 2003; pp. 379-390.

60. Interface Tailoring for Strain-Hardening Polyvinyl Alcohol-Engineered Cementitious Composite (PVA-ECC). 2002. Available online: https:/ / www.researchgate.net/publication/279938212 (accessed on 5 June 2021).

61. Li, M.; Li, V. High-Early-Strength Engineered Cementitious Composites for Fast, Durable Concrete Repair-Material Properties. Available online: https:/ / www.researchgate.net/publication/298499593 (accessed on 5 June 2021).

62. Li, V.C.; Wang, S.X.; Wu, C. Tensile strain-hardening behavior or polyvinyl alcohol engineered cementitious composite (PVA-ECC). Aci Mater. J. 2001, 14, 478.

63. Li, V.; Lepech, M.D. General Design Assumptions for Engineered Cementitious Composites Measuring the Impact of Real-Time Performance Feedback on Multi-Objective Conceptual Building Design Decisions View Project Protein Bound Concrete View Project. 2011. Available online: https:/ / www.researchgate.net/publication/239553672 (accessed on 25 June 2021).

64. Hossain, K.M.A.; Ranade, R.; Li, V. Influence of Aggregate Type and Size on Ductility and Mechanical Properties of Engineered Cementitious Composites. 2009. Available online: https:/ / www.researchgate.net/publication/285773543 (accessed on 25 June 2021).

65. Kanda, T.; Li, V. Effect of Fiber Strength and Fiber-Matrix Interface on Crack Bridging in Cement Composites. J. Eng. Mech. 1999, 125, 290-299. [CrossRef]

66. Li, V.C.; Wu, C.; Wang, S.; Ogawa, A.; Saito, T. Interface Tailoring for Strain-Hardening Polyvinyl AlcoholEngineered Cementitious Composite (PVA-ECC). Aci Mater. J. 2019, 99, M47.

67. Li, V.; Wu, H.C.; Maalej, M.; Mishra, D.K. Tensile Behavior of Engineered Cementitious Composites with Discontinuous Random Steel Fibers Biofuel Production by Pyrolysis of Biomass View Project Structural Characterization and Frictional Properties of Carbon Nanotube/Alumina Composites Prepared by Precursor Method View Project. Available online: https: / /www.researchgate.net/publication/233741819 (accessed on 25 June 2021).

68. Qian, S.; Li, V. Elevating ECC Material Ductility to Structural Performance of Steel Anchoring to Concrete. 2011. Available online: https: / / www.researchgate.net/publication/267938800 (accessed on 25 June 2021).

69. Flexural Behaviors of Glass Fiber-Reinforced Polymer (GFRP) Reinforced Engineered Cementitious Composite Beams. Available online: https: / /www.researchgate.net/publication/279577689 (accessed on 25 June 2021).

70. General Design Assumptions for ECC. Available online: https://www.researchgate.net/publication/268404234 (accessed on 25 June 2021).

71. Angadi, S.; Reddy, K.S.; Selvaprakash, S.; Prasad, J.S.R.; Venu, M. Experimental Studies on Structural Behaviour of Hybrid Fibre Reinforced Concrete. IOP Conf. Ser. Mater. Sci. Eng. 2018, 431, 42003. [CrossRef]

72. Qian, S.; Li, V.; Li, V.C.; Zhang, H.; Keoleian, G.A. Durable and Sustainable Overlay with ECC. 2008. Available online: https:/ / www.researchgate.net/publication/237135081 (accessed on 25 June 2021).

73. Kanda, T.; Li, V.C. New Micromechanics Design Theory for Pseudostrain Hardening Cementitious Composite. J. Eng. Mech. 1999, 125, 373-381. [CrossRef]

74. Li, V.; Mishra, D.; Naaman, A.E.; Wight, J.K.; LaFave, J.M.; Wu, H.-C.; Inada, Y. On the shear behavior of engineered cementitious composites. Adv. Cem. Based Mater. 1994, 1, 142-149. [CrossRef]

75. Ductile Engineered Cementitious Composite Elements for Seismic Structural Applications. 2000. Available online: https://www. researchgate.net/publication/228861959 (accessed on 18 July 2021).

76. Li, M.; Li, V.C. Behavior of ECC/Concrete Layered Repair System Under Drying Shrinkage Conditions/Das Verhalten eines geschichteten Instandsetzungssystems aus ECC und Beton unter der Einwirkung von Trocknungsschwinden. Restor. Build. Monum. 2006, 12, 143-160. [CrossRef] 
77. Yang, E.-H.; Yang, Y.; Li, V. Rheological Control in Production of Engineered Cementitious Composites. Available online: https://www.researchgate.net/publication/279541414 (accessed on 18 July 2021).

78. Li, V. Development of Green ECC for Sustainable Infrastructure Systems Multi-Physics and Multi-Scale Modelling of Next Generation Sustainable Civil Infrastructure View Project Concrete Materials; Engineering Cementious Composites View Project Development of Green Ecc for Sustainable Infrastructure Systems. Available online: https:/ /www.researchgate.net/publication/ 228998310 (accessed on 18 July 2021).

79. A Study on Impact of Polypropylene (Recron 3S) Fibers on Compressive and Tensile Strength of Concrete. IJIRST-Int. J. Innov. Res. Sci. Technol. 2017. Available online: www.ijirst.org (accessed on 18 July 2021).

80. Wu, F.; Xu, L.; Chi, Y.; Zeng, Y.; Deng, F.; Chen, Q. Compressive and flexural properties of ultra-high performance fiber-reinforced cementitious composite: The effect of coarse aggregate. Compos. Struct. 2020, 236, 111810. [CrossRef]

81. Yang, E.-H.; Garcez, E.; Li, V.C. Development of pigmentable engineered cementitious composites for architectural elements through integrated structures and materials design. Mater. Struct. 2011, 45, 425-432. [CrossRef]

82. Experimental Study on the M20 Grade Cement Concrete Containing Crimped Steel Fibres. 2016. Available online: www.ijste.org (accessed on 18 July 2021).

83. Zhou, J.; Qian, S.; Beltran, M.G.S.; Ye, G.; Van Breugel, K.; Li, V.C. Development of engineered cementitious composites with limestone powder and blast furnace slag. Mater. Struct. 2009, 43, 803-814. [CrossRef]

84. Eswari, S.; Raghunath, P.N.; Kothandaraman, S. Regression Modeling for Strength and Toughness Evaluation of Hybrid Fibre Reinforced Concrete. 2011. Available online: https://www.researchgate.net/publication/267785146 (accessed on 18 July 2021).

85. Balanji, E.K.Z.; Sheikh, N.; Hadi, M.N.S.; Sheikh, M.N. Behaviour of High Strength Concrete Reinforced with Different Types of Steel Fibres Sea Sand and Seawater in Concrete View Project Rigid Pavements, Portland Cement Concrete, Geogrid View Project Behaviour of High Strength Concrete Reinforced with Different Types of Steel Fibres. Available online: https: / www. researchgate.net/publication/311708009 (accessed on 18 July 2021).

86. Ghugal, Y.M.; Sabale, V.; Ghugal, Y.M.; Sabale, V.D.; More, S.S. Experimental Investigation on High Strength Steel Fiber Reinforced Concrete with Metakaolin Stability of Plates and Shells View Project Stability of Structures View Project Experimental Investigation on High Strength Steel Fiber Reinforced Concrete with Metakaolin. 2017. Available online: https://www.researchgate.net/ publication/319184021 (accessed on 18 July 2021).

87. Xu, M.; Bao, Y.; Wu, K.; Shi, H.; Guo, X.; Li, V.C. Multiscale investigation of tensile properties of a TiO2-doped Engineered Cementitious Composite. Constr. Build. Mater. 2019, 209, 485-491. [CrossRef]

88. Cheng, Z.; Yan, W.; Sui, Z.; Tang, J.; Yuan, C.; Chu, L.; Feng, H. Effect of Fiber Content on the Mechanical Properties of Engineered Cementitious Composites with Recycled Fine Aggregate from Clay Brick. Materials 2021, 14, 3272. [CrossRef] [PubMed]

89. Turk, K.; Nehdi, M.L. Coupled effects of limestone powder and high-volume fly ash on mechanical properties of ECC. Constr. Build. Mater. 2018, 164, 185-192. [CrossRef]

90. Ding, Y.; Yu, J.-T.; Yu, K.; Xu, S.-L. Basic mechanical properties of ultra-high ductility cementitious composites: From 40 MPa to $120 \mathrm{MPa}$. Compos. Struct. 2018, 185, 634-645. [CrossRef]

91. Yu, K.-Q.; Dai, J.-G.; Lu, Z.-D.; Poon, C.S. Rate-dependent tensile properties of ultra-high performance engineered cementitious composites (UHP-ECC). Cem. Concr. Compos. 2018, 93, 218-234. [CrossRef]

92. Chen, Z.; Li, J.; Yang, E.-H. Development of Ultra-Lightweight and High Strength Engineered Cementitious Composites. J. Compos. Sci. 2021, 5, 113. [CrossRef]

93. Sun, M.; Chen, Y.; Zhu, J.; Sun, T.; Shui, Z.; Ling, G.; Zhong, H.; Zheng, Y. Effect of Modified Polyvinyl Alcohol Fibers on the Mechanical Behavior of Engineered Cementitious Composites. Materials 2018, 12, 37. [CrossRef] [PubMed]

94. Zhou, Y.; Xi, B.; Yu, K.; Sui, L.; Xing, F. Mechanical Properties of Hybrid Ultra-High Performance Engineered Cementitous Composites Incorporating Steel and Polyethylene Fibers. Mater. 2018, 11, 1448. [CrossRef] [PubMed]

95. Nanda, R.P.; Mohapatra, A.K.; Behera, B. Influence of metakaolin and Recron 3s fiber on mechanical properties of fly ash replaced concrete. Constr. Build. Mater. 2020, 263, 120949. [CrossRef]

96. Said, S.; Razak, H.A. The effect of synthetic polyethylene fiber on the strain hardening behavior of engineered cementitious composite (ECC). Mater. Des. 2015, 86, 447-457. [CrossRef]

97. Zhu, Y.; Yang, Y.; Yao, Y. Use of slag to improve mechanical properties of engineered cementitious composites (ECCs) with high volumes of fly ash. Constr. Build. Mater. 2012, 36, 1076-1081. [CrossRef]

98. Strength Characteristics of Glass Fiber Reinforced Concrete (GFRC) using Calcium Chloride Integral Curing Method. Int. J. Recent Technol. Eng. 2019, 8, 3040-3044. [CrossRef]

99. Hajnayeb, A.; Ghasemloonia, A.; Khadem, S.; Moradi, M. Application and comparison of an ANN-based feature selection method and the genetic algorithm in gearbox fault diagnosis. Expert Syst. Appl. 2011, 38, 10205-10209. [CrossRef]

100. Amari, S.; Wu, S. Improving support vector machine classifiers by modifying kernel functions. Neural Netw. 1999, 12, 783-789. [CrossRef]

101. Gordon, L. Using Classification and Regression Trees (CART) in SAS®Enterprise Miner TM For Applications in Public Health. SAS Glob. Forum 2013, 2013, 1987-2012.

102. Zhang, D. A Coefficient of Determination for Generalized Linear Models. Am. Stat. 2017, 71, 310-316. [CrossRef]

103. Pham, B.T.; Son, L.H.; Hoang, T.-A.; Nguyen, D.-M.; Bui, D.T. Prediction of shear strength of soft soil using machine learning methods. Catena 2018, 166, 181-191. [CrossRef] 